\title{
Technological Priorities of Production Technologies Development in the Industrial Sector of Russia
}

\author{
Olga Pudovkina ${ }^{1}{ }^{*}$ Ekaterina Ivanova $^{2}$, Diana Khazanova $^{3}$
}

\author{
${ }^{1}$ Syzran Branch of SSEU, Russia \\ ${ }^{2}$ Michurinsk SAU, Russia \\ ${ }^{3}$ Tambov State Technical University, Russia \\ *Email: olechkasgeu@mail.ru
}

\begin{abstract}
Under the fourth industrial revolution's influence, the industrial phase of development dictates specific requirements for modernising technological processes and industries. This is especially relevant for industry, whose share in the country's GDP is relatively high. In this regard, it becomes vital to establish the industry's future strategic development's contour under external challenges and threats.

The research aimed to predict technological priorities and possible stages of development of advanced production technologies in Russia.

The primary research method was a forecast methodology based on long-term models of an integrated assessment of the world production development and technological market in a scenario form and determining market participants strategic positions. This method revealed the most practical information resources necessary for the research.

This article describes the fundamental processes that will determine the technological sphere of the strategic direction of the industrial sector development associated with the launch of the next innovation and technological cycle.

The result of the research is an integrated forecast of the possible stages of advanced production technologies development and priority of technological development of Russia to modernise the industrial complex under the conditions of deep penetration of digital technologies, based on the concept of a new industrial society. The conclusions on implementing the forecast results will contribute to scientific research to implement structural change programs in the industry.
\end{abstract}

Keywords: Infrastructure, Forecast map, Industry, Technologies, Forecast, Digital environment.

\section{INTRODUCTION}

Modern world trends in economic systems development form a new paradigm of the forecast, which entails fundamental changes in the strategic modernisation processes. The use of forecast methodology is a relatively recent phenomenon that leads to institutionalised scenario forecasting. Lately, the forecast methodology has become extremely popular. It is widely used by state authorities to develop innovation policy, both in industry and in other sectors of the economy in forming a vision of the future. As society's complexity increases, the forecast methodology's scope expands to cover a broader range of issues. This is mainly connected with the increasing importance of technological and organisational innovation, development of the network architecture of economic relations and other phenomena associated with the accelerating globalisation and modernisation of the world economy.

The systemic and complex nature of the tasks in question requires different approaches and innovative planning tools. However, traditional managerial competencies, considered the best up to now, are still necessary but no longer sufficient to succeed in such an unpredictable environment [10].

The forecast is a methodology of system forecast, which has recently appeared globally; in fact, it is a possibility of the future vision. By and large, this is a 
process of strategic planning involving many specialists who forecast the image of "visible tomorrow" and develop directions for the development of the future economy. The forecast scenario model is more flexible, allowing to see all the options for the events developing.

The industry is a key and priority area for developing the Russian economy, whose overall contribution to Russia's GDP is relatively high. Transformation of the industry is a long-felt need; it reflects the transition of the industrial sector from one technological structure to another to increase the efficiency and competitiveness of an enterprise and, in general, the Russian economy. In this regard, it is necessary to develop long-term forecasts of the industrial sector development in a scenario form and determine strategic priorities under external challenges and threats. Application of these forecasts would ensure Russia's sustainable development and competitiveness over a long period, indicating the study's relevance.

What trends will be the main trends in the industry? What trends will determine the development of the sector? What technologies are crucial for the country? these are fundamental questions.

Forecast methodology should help identify critical promising areas of technological growth in the industry. Two documents are intended to support this vector: The Strategy for the Scientific and Technological Development of the Russian Federation for the LongTerm Period and the Strategy for the Development of the Electronic Industry of Russia [1,2].

The industrial priority of the strategy is quite comprehensive and covers the transition to the electronics industry, reconstruction and technical reequipment of production facilities, creation of new technological directions, development of breakthrough electronic industrial technologies, etc. Other strategic priorities are also devoted to the wide application of digital intelligent industrial technologies, machine learning and artificial intelligence, the transition to highperformance and sustainable industrial production, and smart systems. These priorities correspond to the ambitious tasks outlined in the document earlier.

The analysis showed that the strategies emphasise priorities in the field of industry. Simultaneously, relatively less attention is paid to developing an integrated forecast of industry's technological development. Forecasting in industrial technologies will provide the basis for the state industrial policy, facilitating its strategic goals. This goal can be achieved by coordinating the Ministry of Industry and Trade of the Russian Federation's scientific and technological policy with the scientific, technological and socio-economic forecasting system created in the country.

The article is a methodology of systemic forecasting of long-term technological changes to update the strategic vector of industrial development, consistent with the context and content of the country's industrial policy.

\section{METHODOLOGY}

To solve research problems, the authors used a set of scientific methods. The theoretical and methodological basis was the necessary provisions for studying processes and phenomena: system analysis, abstraction, analysis and synthesis. The primary method was the forecast methodology, which includes a wide range of research methods: horizon scanning, scenario analysis, market prospects and technologies. This method revealed the most practical information resources necessary for the ongoing study.

The forecasting approach used in the study differs from standard methods. Forecast methodology is based on long-term models of integrated assessment of the development of the world production and technological market in a scenario form and determining market participants' strategic positions.

Forecast methodology is not a substitute for longterm planning; it is a tool for improving strategic planning quality and accuracy. The forecast methodology application makes it possible to define the main directions of strategic modernisation of the national economy's priority sectors more clearly, particularly industrial enterprises.

Scenarios are often used in future industry-related studies. Studies using scenario forecasting are based on purely econometric modelling, statistical analysis, partial equilibrium modelling and similar methods $[4,7]$. The scenarios developed in this study are based on a combination of qualitative and quantitative methods.

For critical processes that will determine the technological scope of industrial sector development's strategic directions, appropriate resources have been selected for further analysis. They are the basis of the following visualisations:

- prognostic maps;

- trend maps.

This analysis was supplemented with a horizontal scan, which included a literature review applied to identify technological trends in the industry.

\section{RESULTS}

Industry 4.0 transforms business models of production firms [3]. In the next 10-15 years, industrial production will have to carry out a set of tasks that have a fundamental significance. The industry must cope with the growing complexity of production and organisation of technological chains and products' complexity. To 
control this complexity, a high-quality breakthrough in engineering and process control is required.

Worldwide, the result of a technological forecast is technology consortia. Their creation aims to develop technological regulations and standards for their subsequent recording at the state industrial policy level, considering the market's general situation. The result of the technological forecast should be the construction of a specific structure, in which it will be clear how the future will develop.

The key processes that, in our opinion, will determine the technological sphere of the strategic directions of the development of the industrial sector will be associated with the launch of the next innovation and technology cycle, the implementation of three interconnected "revolutions":

1. For 5-7 years, one of the dominant processes will be the transfer of imports of information platforms, which are the basis for the design. If we do not provide the design with modern tools, then we will leave any production process in the world. This is a "revolution" in the design and organisation of production processes;

2. New materials. The peculiarity is that revolution in design revolutionises these materials;

3. "Revolution" in infrastructures: "smart environments," a system of "smart things" to overcome the linear architecture of traditional industrial architectures.

Development of the traditional industrial industry has substantial restrictions associated with the old raw material base. With the existing limits, the industry will not be able to develop. Also, traditional industrial infrastructures are deployed under the senior industry and, in general, inflexible and too expensive for radical, innovative systems. The era of innovation of entire systems requires new, more flexible, more open and more efficient infrastructures.

Changing the "technological paradigm" requires selecting those transformations that extend to all industries or most of them and lead not to optimisation, but radical changes in the industry.

The industry is currently undergoing total technological and organisational reengineering, based on the complete digitisation of production processes, life cycle management with the transition to an open and modular architecture (figure 1).

In the 1960-1980s, the reengineering process was launched. A decision was made to optimise and automate an intellectual activity, change the nature of design, and ensure complex technological systems' template design. When workstations entered the market, the breakthrough took place, the volume of computer programs that provided speed, accuracy, reproducibility, archiving of knowledge increased. In 2010, another critical solution

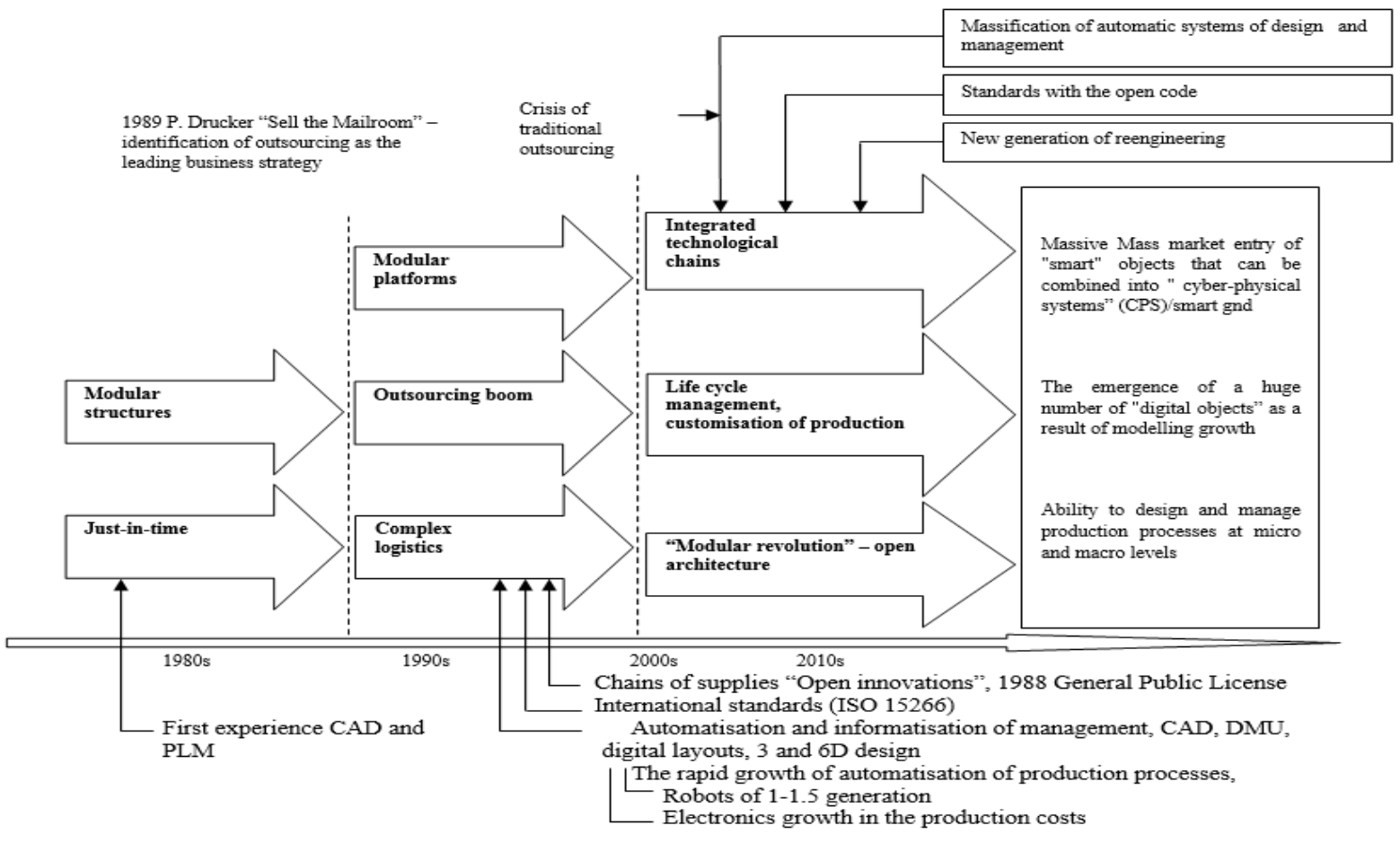

Figure 1 Map of technological and organisational reengineering.

*compiled by the authors based on research. 
was the transition to modular designs which saved human costs and time. At that moment, there was the institutionalisation of production, automatisation. The key benefit here was that computer engineering developed, providing control of complex equipment at speeds in the difficulty zone, exceeding the human response.

In the prevailing digitalisation trends, most enterprises seeking efficient operations must go through digital transformation [9]. In practice, this means moving from a modular architecture to an integrated digital architecture. The scenario model of the forecast of industrial development, developed by the authors, is presented in figure 2 .

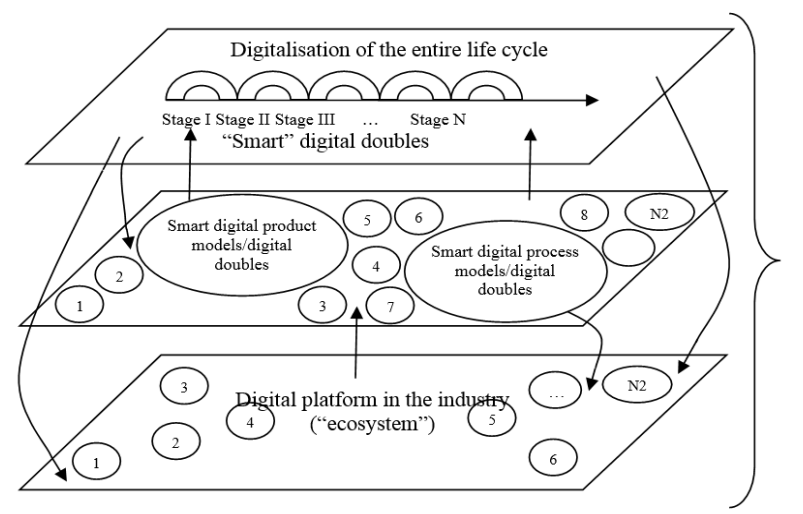

Figure 2 Forecast Map of Industry Developmen.

*compiled by the authors based on research.

This is how the software had automated design works - groups of programs that provide volumetric design control with the overall lifecycle mode production process.
Detailed design and management processes are revolutionary; they allow you to customise production, create open modular platforms and build effective lifecycle management. The analysis showed that specialised software products in industry branches focus first on digital design and digital management.

The next critical process that will determine the technological sphere of the industrial sector's strategic direction is new materials and their integration into computer-aided design systems. The construction is designed with these materials at once, not the compositional material (figure 3 ).

The transition to new industrial materials has two main goals: to obtain unique qualities (achieving high resistance) and new product economics (efficiency of the full product). They are gained using exceptional design and production technologies, both materials and products.

The next important point is the integration of the processes into the digital infrastructure system. Forecast made it possible to form a specific horizon for technological systems development (figure 4). Digital environments are future-generation architectures. A large volume of various kinds of mechanisms linking the digital and material world underlies them. The task is non-trivial. Today, Russia uses the first-generation SMART series; these are the so-called adjustable smart systems, SCAD systems of the fourth generation installed based on smart sensors. In 2025-2030, we will receive SMAT rows of the next generation, the so-called selfgoverning systems. A package of infrastructures will soon be deployed for the next evolutionary step in developing all things, for the following type of human behaviour.

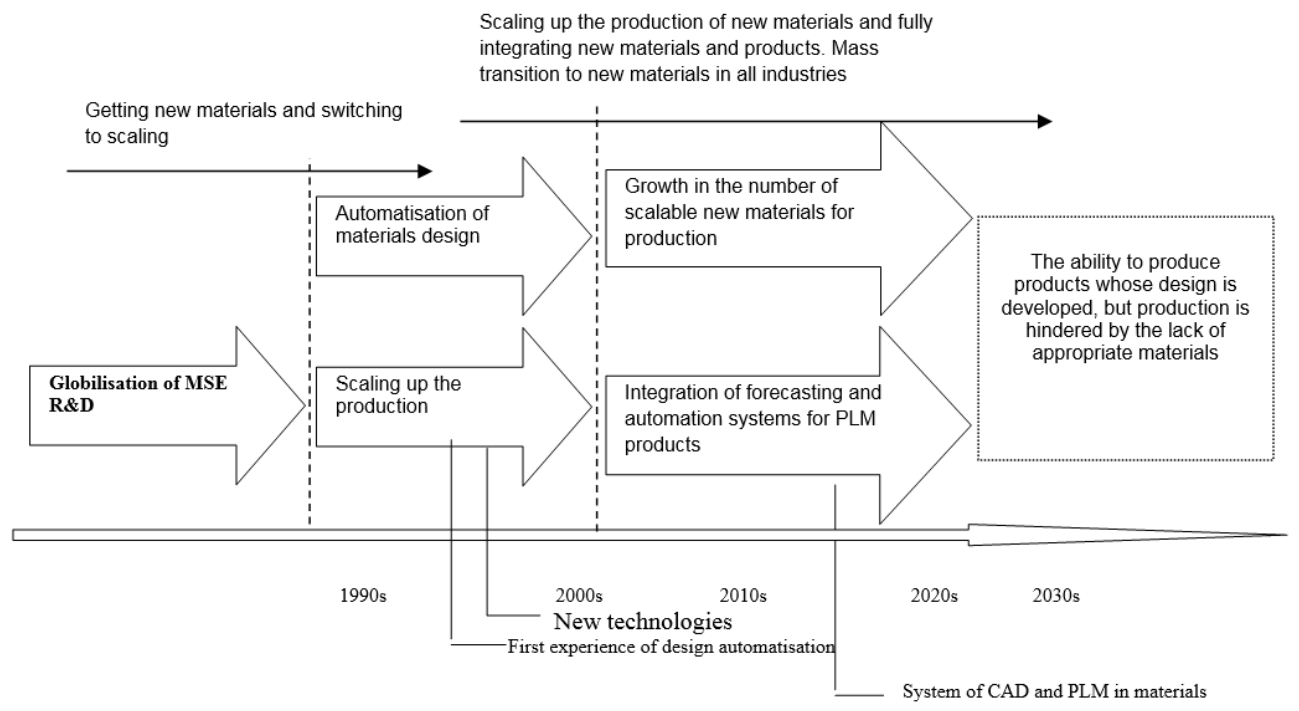

Figure 3 Transition to new materials as a critical technological breakthrough.

*compiled by the authors based on research. 


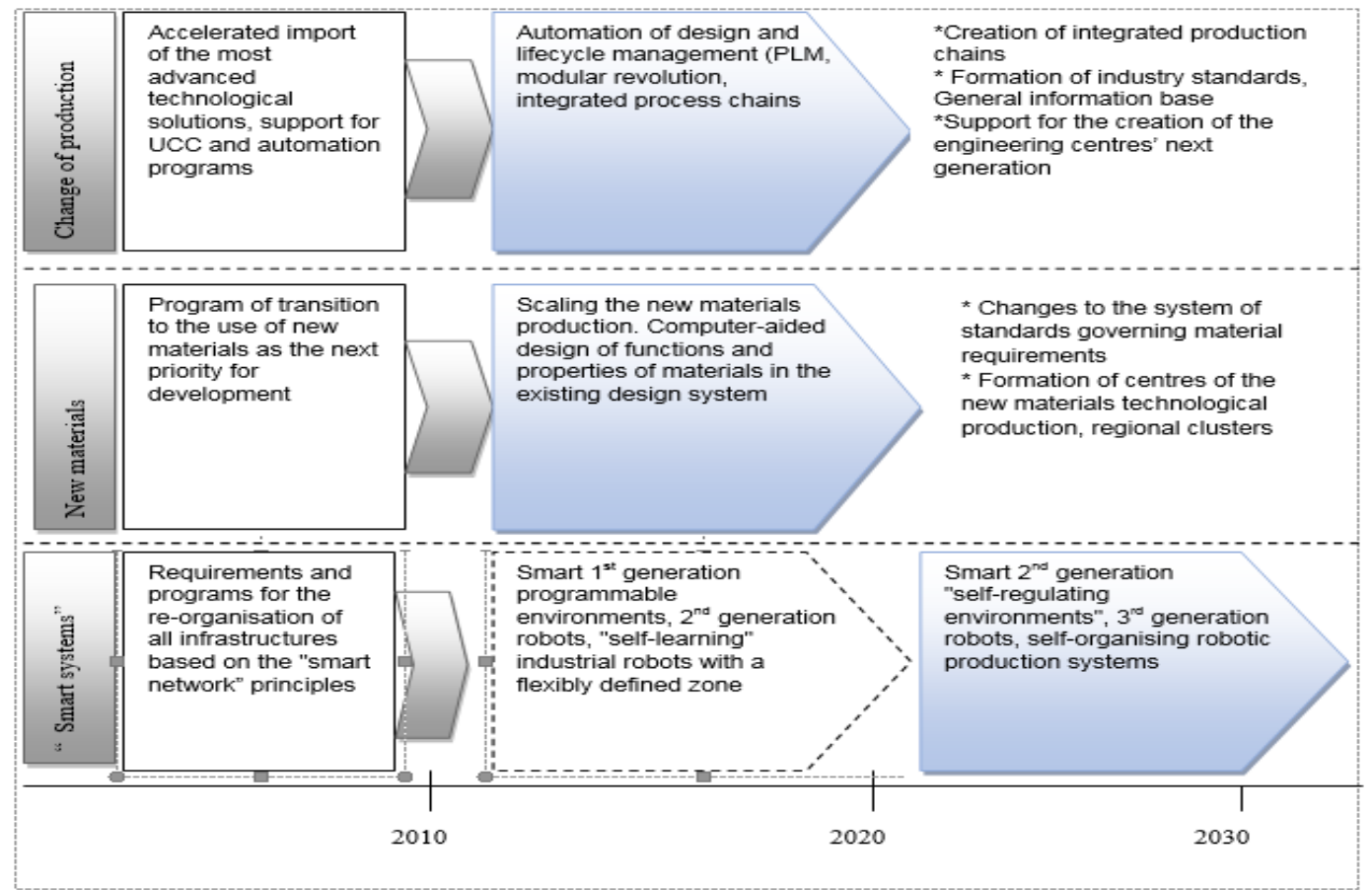

Figure 6 Possible stages of development of advanced production technologies.

*compiled by the authors based on research.

Technological progress in industrialised countries was supported by three generations of government programs in advanced production technologies. Promising advanced industrial technologies is a complex of unconventional materials, automation and intellectualisation of production technological processes and systems (figure 5).

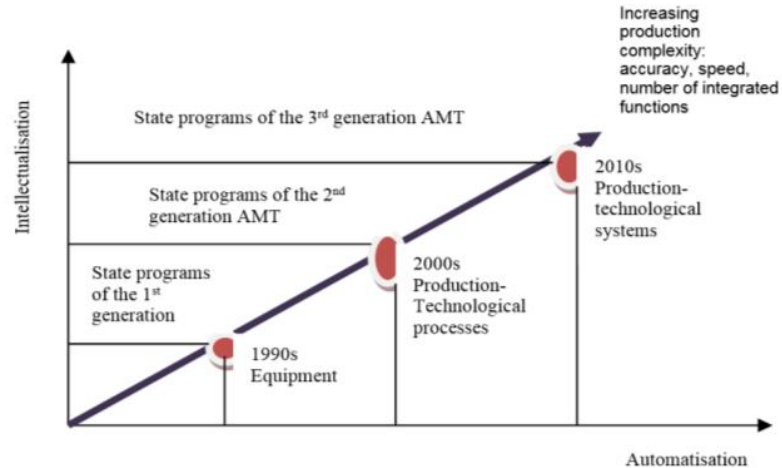

Figure 5 Advanced Industrial Technologies.

*compiled by the authors based on research.

Figure 5 shows that in the 1990s, technological programs were focused on equipment (CTU, robots, digital controllers, sensors, etc.). In the 2000s, they entered the processes and systems of engineering labour, design and management of production processes began to model production and technological processes. In 2010, these were self-regulatory production and technological systems. What will the near future hold? In our opinion, this is the emergence of integrated design digital platforms, smart materials with unique properties (selfdesign, self-healing, generation of information signals). The use of smart materials will increase.

It is no secret that the entire system of engineering of digital technology systems is now being imported. Russia will need 5-7 years to become a supplier of engineering software. Today's situation does not ensure competitiveness among other suppliers of the given systems. The main two companies' main questions are how to reach a single information and project platform and ensure its viability and effectiveness.

There are already global digital catalogues that allow you to access a digital image or description for smart materials. There is no such catalogue in Russia, although many new developments are underway. The problem is that we will have to combine the development of materials and structures, and we do not have a general idea of the variability of tools for using these new materials. This system has not been fully completed in the whole world. Smart materials for Russia are the area of 2025-2030. Based on the analysed information, the authors developed possible forecasts of advanced production technologies for Russia (figure 6)

According to "Smart Series" technologies, we are not the first, and we are not the last since smart rows are still in the commercialisation zone or the demonstration project zone. We can participate in the advanced 
technological process, adopting standards; the problem is to extend relevant practices to Russian companies' work.

The industry's image, which will be in the next 10-15 years, is ultra-accuracy, super-speed, super-complexity based on automation and intellectualisation, and complex information tools infrastructures.

\section{DISCUSSION}

The necessity of strategic modernisation of industrial enterprises was emphasised in the work Strategic Elements in product Innovation in Industrial Firms, where strategy is defined as the art of using all available tools to achieve the desired goal [6]. Modernisation means the transition to a new phase of civilisational development, which requires a fundamental renewal of all economic growth components [5].

The strategy is a common document that should be supported by action plans, government programs and other lower-level documents that specify the exact steps and resources to identify the priorities developed [8].

The work focuses on transforming the industry in connection with the entry into a new phase of industrial development under the fourth industrial revolution's influence. It is vital to urgently implement breakthrough development to overcome Russia's lag behind world leaders [9].

The analysis of the critical processes of the technological breakthrough led to several conclusions and recommendations. The technological explosion of $70-80 \mathrm{~s}$ is associated with computer technologies that made it possible to accumulate technological processes, not in paper documentation, but a record of numerical models. Technology has been used in various ways to combat the growing complexity. At the beginning of 2010 , it became clear that the next technological breakthrough was necessary to be launched and advanced production technologies involved in the process. Growth should not come at the expense of workers and capital, but through new scaled electronic systems (figure 7).

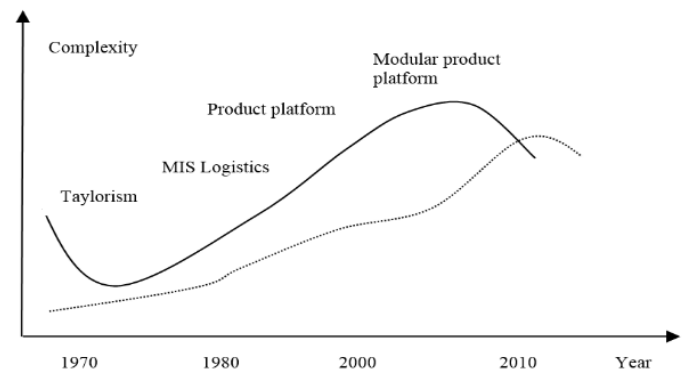

Figure 7 Growth of technological systems complexity.

*compiled by the authors based on research.
Therefore, the transition to the fourth industrial revolution is an inevitable innovation process that will result in fully automated digital production with the prospect of integration into a global industrial ecosystem [9].

\section{CONCLUSION}

The results of the study are of crucial economic importance, which involves establishing a forecast for the development of production and technological provisions for the modernisation of the industrial complex in the conditions of reindustrialisation, the implementation of which can serve as a factor in increasing Russia's competitiveness at the global level.

The article analyses the fundamental processes that will determine the technological sphere of the strategic directions of industrial sector development related to the launch of the next innovation and technology cycle and the implementation of three interconnected "revolutions."

The authors concluded that under the conditions of reindustrialisation and the Russian economy's breakthrough development, it is advisable to use industry image scenario models. The conclusions on implementing the forecast results will facilitate scientific research to implement structural change programs in the industry.

\section{REFERENCES}

[1] Decree of the Government of the Russian Federation "On approval of the state program of the Russian Federation "Scientific and technological development of the Russian Federation" from 29 March 2019, Iss. 377, Moscow.

[2] Decree of the Russian Federation's Government from 17 January 2020, No. 20-R "On the Russian Federation electronic industry development strategy for the period up to 2030 and the action plan for its implementation."

[3] Bai Chunguang, Dallasega Patrick, Orzes Guido, Sarkis Joseph, Industry 4.0 technologies assessment: A sustainability perspective, Contents lists available at Science Direct International Journal of Production Economics, International Journal of Production Economics 229 (2020) 107776.

[4] 4.Capros P. et al., Outlook of the EU energy system up to 2050: the case of scenarios prepared for European Commission's "clean energy for all Europeans" package using the PRIMES model, Energy Strategy Rev 22 (2018) 255-263. 
[5] Faskhutdinov Azat, Innovation and Business Management Modernisation of the Russian economy in terms of innovative development, 4th International Conference on Leadership, Technology, Procedia - Social and Behavioural Sciences 210 (2015) 188-192.

[6] Fenişer Cristina, Popescu Daniela, Sadeh Arik, 25th International Strategic Elements in Product Innovation in Industrial Firms Conference on Production Research Manufacturing Innovation: Cyber-Physical Manufacturing August 9-14, 2019, Chicago, Illinois (USA).

[7] Melikoglu M., Vision 2023: scrutinising Turkey's electricity capacity targets' achievability and generating scenario-based nationwide electricity demand forecasts, Energy Strategy Rev. 22 (2018) 188-195.

[8] Proskuryakova Liliana, Forecast for the "energy" priority of the Russian Science and Technology Strategy National Research University Higher School of Economics, Energy Strategy Reviews 26 (2019) 100378.

[9] Pudovkina O., Ivanova E., Industrial Digital Transformation and Ecosystem Formation Based on Advanced Digital Platforms Current Achievements, Challenges and Digital Chances of KnowledgeBased Economy, pp. 507-518, Cite as Chapter First Online: 30 May 2020.

[10] Silva Marisa, A systematic review of Forecast in Project Management literature, Conference on ENTERprise Information Systems, International Conference on Project MANagement, Conference on Health and Social Care Information Systems and Technologies, CENTERIS, ProjMAN, HCist 2015 October 7-9, 2015, Procedia Computer Science 64 (2015) 792-799. 